\title{
Air Pollutants are associated with Dry Eye Disease in Urban Ophthalmic Outpatients: a Prevalence Study in China
}

\author{
Donghui Yu $u^{1,2}$, Qinglong Deng ${ }^{3}$, Jiwei Wang ${ }^{3}$, Xing Chang ${ }^{4}$, Shuxiao Wang ${ }^{4}$, Renren Yang ${ }^{3}$, Jinming $\mathrm{Yu}^{3 *}$ \\ and Jing $Y u^{1 *}$ (D)
}

\begin{abstract}
Background: Although previous prevalence studies of DED were reported from some countries worldwide, national data are unavailable in China. We aimed to conduct an up-to-date national survey on the prevalence of DED in China and find out the potential risk factors including air pollutant.

Methods: 23,922 eligible outpatients were recruited from ophthalmic clinics of 32 cities in China in 2013 by registration orders. The patients' demographic characteristics, history of keratorefractive surgery, diseases and medication history were collected and the daily air pollutant data in 2013. Multivariate logistic analysis was performed to identify the potential risk factors associated with DED. The association between related factors and dry eye diseases subtypes evaluated as $\mathrm{p}$ value and odds ratios (OR) with 95\% confidence intervals (Cl).

Results: Among 23,922 outpatients, the prevalence of DED was $61.57 \%$, and that of the male patients was $57.64 \%$ and of the female was $65.32 \%(P<0.0001)$. Multivariate logistic regression suggested that the possible risk factors for DED included: female, older age, history of keratorefractive surgery, presence of arthritis, thyroid diseases, and antihistamine, diuretic, duodenal ulcer drugs, diazepam. Air pollutants including $\mathrm{O}_{3}, \mathrm{PM}_{2.5}$ and $\mathrm{SO}_{2}$ were also identified as the risk factors.

Conclusion: The prevalence of DED among ophthalmic outpatients in China was considerably high. Age, gender, history of keratorefractive surgery, diseases, medication history, and air pollutants were associated with DED prevalence.
\end{abstract}

Keywords: Air pollutant, China, Dry eye disease, Prevalence study

\section{Background}

The concept of tear deficiency was first proposed in 1903 by Schirmer, who developed the Schirmer test 90 [1]. Several definitions about Dry Eye Disease (DED) were proposed in the next 100 years [2]. But the most widely accepted definition of Dry Eye was provided by the International Dry Eye Workshop in 2007, referring it as a

\footnotetext{
*Correspondence: jmy@fudan.edu.cn; dryujing@aliyun.com

${ }^{1}$ Department of Ophthalmology, Shanghai Tenth People's Hospital, School of Medicine, Tongji University, No. 301, Yanchang Road, Shanghai, China

${ }^{3}$ Institute of Clinical Epidemiology, School of Public Health and Key Laboratory of Public Health Safety, Ministry of Education, Fudan University, No. 138, Yixueyuan Road, Shanghai, China Full list of author information is available at the end of the article
}

multifactorial disease of the tears and ocular surface that results in symptoms of discomfort, visual disturbance, and tear film instability, with potential damage to the ocular surface. It is accompanied by increased osmolarity of the tear film and inflammation of the ocular surface [3]. In 2014, the Asia Dry Eye Society (ADES) published a new definition about DED as "Dry eye is a multifactorial disease characterized by unstable tear film causing a variety of symptoms and/or visual impairment, potentially accompanied by ocular surface damage." [4].

Patients with DED complain most frequently of a scratchy or sandy (foreign body). Other common symptoms are itching, excessive mucus secretion, inability to produce tears, aburning sensation, photosensitivity, 
redness, pain, and difficulty in moving the lids. The most characteristic feature is interruption or absence of the tear meniscus at the lower lid margin. Early in the course of dry eye syndrome, vision is slightly impaired. As the condition worsens, discomfort can become disabling. In advanced cases, corneal ulceration, corneal thinning, and perforation may develop. Secondary bacterial ingestion occasionally occurs, and corneal scarring and vascularization may result in marked reduction in vision. Early treatment may prevent these complications.

Surveys showed wide range of DED prevalence, from around $2.1 \%$ to $35 \%$ and Asians was more susceptible than Caucasians and elderly women with are of higher risk $[5,6]$. Some factors were independently and significantly associated with dry eye including history of arthritis, smoking status, caffeine use, history of thyroid disease, history of gout. Older age and illiteracy were also predictors of DED [7-9].

Air pollution has been linked to human diseases including respiratory disease, cardiovascular disease, kidney parenchyma cancer and so on [10-13]. Meanwhile, DED test outcomes assessing the ocular surface integrity and tear stability are climate dependent [14]. But there were few evidences about the relationship between DED and air pollution.

Despite several studies regarding the epidemiology and risk factors of DED, most of them were derived from populations with limited sample size, and few studies analyzed the risk factors comprehensively. In addition, a study focusing on Chinese DED population has not been reported and a study about the association between air pollution and DED is still lacking. In this setting, the current study aimed to understand the epidemiology of DED among ophthalmic outpatients from different cities in China, and to analyze the associated risk factors including air pollutants.

\section{Materials and methods}

\section{Study population}

In this study, 79 hospitals (or research centers) with ophthalmology clinics were randomly selected from 32 cities in China from July to December in 2013. Inclusion criterion of outpatients was a presence of at least one of these six symptoms: dry sensation, foreign body sensation, burning sensation, eyesight fatigue, discomfort, and vision fluctuation. Patients with other eye diseases such as conjunctivitis, glaucoma, and ocular trauma were excluded. Eventually, 23,922 eligible subjects were included in our study.

\section{Data collection}

We collected the following information of the patients including: demographic characteristics (age and gender), history of keratorefractive surgery, history of diseases (diabetes, arthritis and thyroid diseases), and medication history (antihistamine, oral contraceptive, diuretic, duodenal ulcer drugs, and diazepam). Patients' age were divided into 3 group based on the questionnaire. Clinical examinations including tear breakup time tests, Schirmer I tests and fluorescein staining were also conducted among these patients. All of the predictors were selected from clinic practice, expertise [15] and significant variables of Univariate analysis.

To study the relationship between air pollution and DED, we collected the daily air pollutant data (CO: average concentration in $24 \mathrm{~h}, \mathrm{NO}_{2}$ : average concentration in $24 \mathrm{~h}, \mathrm{O}_{3}$ : average concentration in $24 \mathrm{~h}, \mathrm{PM}_{10}$ : average concentration in $24 \mathrm{~h}, \mathrm{PM}_{2.5}$ : average concentration in $24 \mathrm{~h}, \mathrm{SO}_{2}$ : average concentration in $24 \mathrm{~h}$ ) and yearly meteorological data (relative humidity, mean air pressure, and air temperature) of the 32 China cities from January 1, 2013 to December 31, 2013. Air pollutant data is kindly provided by School of Environment, Tsinghua University. Taking the 75th quantile of the pollutant concentration as "extreme value" $(\mathrm{CO}$ : $1.47 \mathrm{mg} / \mathrm{m}^{3}, \mathrm{NO}_{2}: 52.83 \mu \mathrm{g} / \mathrm{m}^{3}, \mathrm{O}_{3}: 79.06 \mu \mathrm{g} / \mathrm{m}^{3}, \mathrm{PM}_{10}$ : $148.91 \mu \mathrm{g} / \mathrm{m}^{3}, \mathrm{PM}_{2.5}: 81.21 \mu \mathrm{g} / \mathrm{m}^{3}, \mathrm{SO}_{2}: 43.40 \mu \mathrm{g} / \mathrm{m}^{3}$ ), we calculated the number of days in which pollutant concentration exceeds "extreme value" in each city in 2013, and then we divided the number of days into two groups according to 75th percentile.

This DED survey was approved by Medical Research Ethics Committee of School of Public Health, Fudan University. Details and procedures of this study were indicated to all the patients by practitioners before the survey and clinical tests. Informed consent was obtained from all the subjects. Participants who disagreed with this survey would be excluded, thus, in this way we documented and insured all patient consents.

\section{Diagnosis of DED}

Diagnosis was established according to a consensus of Chinese dry-eye diagnostic criteria from the Chinese Medical Association [16] as follows: (1) presence of at least one of the six symptoms: dry sensation, foreign body sensation, burning sensation, eyesight fatigue, discomfort and vision fluctuation; (2) TBUT $\leq 5 \mathrm{~s}$ or Schirmer I test (without anesthesia) $\leq 5 \mathrm{~mm} / 5 \mathrm{~min}$; (3) a positive diagnosis of fluorescein staining accompanied by one of the results: $5 \mathrm{~s}<\mathrm{TBUT} \leq 10 \mathrm{~s}$ or $5 \mathrm{~mm} / 5 \mathrm{~min}<$ Schirmer I test (without anesthesia) $\leq 10 \mathrm{~mm} / 5 \mathrm{~min}$. The presence of (1) was essential for disease diagnosis. Subjects showing the presence of a combination of (1) and (2), or (1) and (3) were diagnosed with DED. 


\section{Statistical analysis}

Data analyses were performed using SAS 9.4 and R 3.4.1. The significance level was set at 0.05 and all the tests were two-sided. Descriptive statistics, and univariate analysis as well as multivariate analysis were both conducted. The DED prevalence of the whole population and different gender as well as age groups were calculated respectively. Pearson Chi square test was applied for enumeration data. A binary non-conditional logistic model was performed to conduct multivariate regression analysis. The dependent variable was the status of DED $(1=$ yes, $0=$ no). The independent variables were the potential related factors as listed in Table 1, including demographic characteristics, history of keratorefractive surgery, diseases and medication history, as well as the daily air pollutant data. Yearly average of relative humidity, mean air pressure, and air temperature were controlled as confounding factor. The stepwise method was adopted to select significant independent variables.

\section{Results}

\section{General information}

Among 23,922 outpatients, $51.16 \%$ were female, and $45.54 \%$ were aged from 25 to 45 years old. There were few patients with the history of keratorefractive surgery (15.02\%), diabetes (8.34\%), arthritis $(8.02 \%)$, or thyroid diseases $(5.93 \%)$. Also, few of them had the history of using antihistamine, oral contraceptive (OC), diuretic, duodenal ulcer drugs (DU drugs) and diazepam. The corresponding percentage were $6.3 \%, 3.34 \%, 4.18 \%, 2.35 \%$, and $3.14 \%$, respectively.

Detailed information and the DED prevalence among different groups were as shown in Table 1. Significant differences of DED prevalence could be found in different gender $(\mathrm{P}<0.0001)$; age groups $(\mathrm{P}<0.0001)$; history of keratorefractive surgery $(\mathrm{P}<0.0001)$, diabetes $(\mathrm{P}<0.0001)$, arthritis $(\mathrm{P}<0.0001)$, and thyroid diseases $(\mathrm{P}=0.0008)$; history of using antihistamine $(\mathrm{P}<0.0001)$, OC $(\mathrm{P}=0.0106)$, diuretic $(\mathrm{P}<0.0001)$, DU drugs $(\mathrm{P}<0.0001)$, and diazepam $(\mathrm{P}<0.0001)$. There were also significant differences of $\mathrm{DED}$ prevalence among the following air pollutants: $\mathrm{CO}(\mathrm{P}=0.0116), \mathrm{O}_{3}$ $(\mathrm{P}<0.0001), \mathrm{PM}_{10}(\mathrm{P}<0.0001), \mathrm{PM}_{2.5} \quad(\mathrm{P}=0.0249)$ and $\mathrm{SO}_{2}(\mathrm{P}<0.0001)$.

The characteristics of the air pollutants in different cities was shown in Table 2 (only the first and last three cities sorted by the days that the pollutant concentration exceeds the "extreme value" were listed).

\section{Epidemiological characteristics of DED}

The prevalence of DED was $61.57 \%$ among 23,922 outpatients, and that of the male patients was $57.64 \%$ and of
Table 1 Characteristics and DED prevalence of the study population

\begin{tabular}{llllll}
\hline Characteristics & $\begin{array}{l}\text { Number } \\
\text { of subjects (\%) }\end{array}$ & $\begin{array}{l}\text { Number } \\
\text { of patients prevalence } \\
\text { with DED }\end{array}$ & $\begin{array}{l}\text { Chi } \\
\text { (\%) }\end{array}$ & P value \\
& & & & $149.0810<0.0001$ \\
\hline $\begin{array}{l}\text { Gender } \\
\text { Male }\end{array}$ & $11,686(48.85)$ & 6736 & 57.64 & & \\
Female & $12,236(51.15)$ & 7993 & 65.32 & & \\
Age (years old) & & & & $351.0333<0.0001$ \\
$<25$ & $4969(20.77)$ & 2579 & 51.90 & & \\
$25-45$ & $10,895(45.54)$ & 6648 & 61.02 & & \\
$>45$ & $8058(33.68)$ & 5502 & 68.28 & &
\end{tabular}

Keratorefractive surgery

$$
\text { No }
$$

Yes

Diabetes

No

Yes

Arthritis

$$
\text { No }
$$

Yes

Thyroid diseases

No

Yes

Antihistamine

No

Yes

OC

No

Yes

Diuretics

No

Yes

DU drugs

No

Yes

Diazepam

No

Yes

$\mathrm{CO}$ (days) $^{*}$

$<124$

$\geq 124$

$\mathrm{NO}_{2}$ (days)*

$<150$

$\geq 150$

$\mathrm{O}_{3}$ (days)*

$<125$

$\geq 125$

$\mathrm{PM}_{10}$ (days)*

$<102$

$\geq 102$

$\mathrm{PM}_{2.5}$ (days)*

$<143$

$\geq 143$
$43.5570<0.0001$

$20,330(84.98) \quad 12,340 \quad 60.70$

66.51

$32.7384<0.0001$

$21,926(91.66) \quad 13,381 \quad 61.03$

67.54

$136.1486<0.0001$

$22,003(91.98) \quad 13,309 \quad 60.49$

$1919(8.02) \quad 1420$

74.00

$11.1371 \quad 0.0008$

22,503 (94.07) 13,796

61.31

65.75

$65.9711<0.0001$

$22,414(93.70) \quad 13,652 \quad 60.9$

$1508(6.30) \quad 1077$

71.42

$6.5310 \quad 0.0106$

23,122 (96.66) 14,271

61.72

57.25

$33.8723<0.0001$

$22,921(95.82) \quad 14,025 \quad 61.19$

$1001(4.18) \quad 704 \quad 70.33$

$23,361(97.65) \quad 14,297 \quad 61.20$

$561(2.35) \quad 432 \quad 77.01$

$23,170(96.86) \quad 14,154 \quad 61.09$

$752(3.14) \quad 575$

76.46

$17,338(72.48) \quad 10,760$

62.06

60.28

15,968 (66.75) $9771 \quad 61.19$

$7954(33.25) \quad 4958 \quad 62.33$

$17,770(74.28) \quad 9733 \quad 54.77$

$6152(25.72) \quad 4996$

81.21

$15,071(63.00) \quad 8989 \quad 59.64$

$8851(37.00) \quad 5740 \quad 64.85$

$17,195(71.88) \quad 10,663 \quad 62.01$

$6727(28.12) \quad 4066 \quad 60.44$ $\begin{array}{ll}2.9279 & 0.0871\end{array}$

$57.8380<0.0001$

$72.7696<0.000$

$6.3735 \quad 0.0116$

$63.8984<0.000$

5.03220 .0249 
Table 1 (continued)

\begin{tabular}{lrrrrr}
\hline Characteristics & $\begin{array}{l}\text { Number } \\
\text { of subjects (\%) }\end{array}$ & $\begin{array}{l}\text { Number } \\
\text { of patients } \\
\text { with DED }\end{array}$ & $\begin{array}{l}\text { DED } \\
\text { (\%) }\end{array}$ & $\begin{array}{c}\text { Chi } \\
\text { Square }\end{array}$ & P value \\
\hline $\mathrm{SO}_{2}$ (days)* & & & & $256.7553<0.0001$ \\
$<101$ & $17,555(73.38)$ & 10,276 & 58.54 & & \\
$\geq 101$ & $6367(26.62)$ & 4453 & 69.94 & & \\
Total & $23,922(100.00)$ & 14,729 & 61.57 & - & - \\
\hline
\end{tabular}

* The number of days in which the pollutant concentration exceeds the "extreme value"

the female patients was $65.32 \%(\mathrm{P}<0.0001)$. The patients whose age was younger than 25 years old had a prevalence of $51.90 \%$, patients whose age was between 25 and 45 years old had a prevalence of $61.02 \%$, and patients whose age was older than 45 years old had a prevalence of $68.28 \%(\mathrm{P}<0.0001)$. The prevalence of DED in different areas and cities were shown in Figs. 1 and 2. The highest prevalence of DED in China was in northern area and the lowest was in central area. The cities with the highest prevalence and lowest prevalence of DED were Zunyi and Shantou, respectively.

\section{Multivariate logistic regression analysis of risk factors for DED}

Multivariate logistic regression analysis suggested that the potential risk factors for DED were: female, older age, history of keratorefractive surgery, presence of arthritis, thyroid diseases, history of using antihistamine, diuretic, DU drugs, diazepam, and air pollutants including $\mathrm{O}_{3}$, $\mathrm{PM}_{2.5}$ and $\mathrm{SO}_{2}$. While, history of using $\mathrm{OC}$ and the air pollutant $\mathrm{CO}$ and $\mathrm{NO}_{2}$ may be the potential protective factors for DED. However, history of diabetes and $\mathrm{PM}_{10}$ were not associated with DED. Detailed information was shown in Table 3.

\section{Discussion}

DED were very common in this population-based sample of ophthalmic outpatients in China. This study suggested that the prevalence of DED in outpatients increased with age and female had a higher prevalence. In previous reports, the prevalence of dry eye disease varied according to the diagnostic criteria, population, and age distribution. But this study of ophthalmic outpatients in China indicated a higher prevalence of dry eye compared with other studies $[5,6]$ because we got the data from ophthalmic clinics instead of communities.

In recent years, more and more attention has been paid to the relationship between dry eye disease and environmental factors. As a type of dry eye disease, dry eye caused by environmental factors may be affected by various aspects [17] including high altitude, wind, and
Table 2 Characteristics of the air pollutants in different cities

\begin{tabular}{|c|c|c|c|}
\hline Type & City & Median (P25-P75) & Days* \\
\hline \multirow[t]{7}{*}{$\mathrm{CO}$} & Tianjin & $1.72(1.37-2.29)$ & 250 \\
\hline & Xi'an & $1.70(1.26-2.47)$ & 211 \\
\hline & Xingtai & $1.54(1.11-2.46)$ & 198 \\
\hline & - & - & - \\
\hline & Guangzhou & $1.00(0.89-1.19)$ & 27 \\
\hline & Fuzhou & $0.73(0.63-0.94)$ & 10 \\
\hline & Guiyang & $0.77(0.63-0.95)$ & 10 \\
\hline \multirow[t]{7}{*}{$\mathrm{NO}_{2}$} & Xingtai & $61.79(47.67-82.99)$ & 232 \\
\hline & Chengdu & $51.76(42.45-65.44)$ & 178 \\
\hline & Ji'nan & $49.70(35.48-68.42)$ & 162 \\
\hline & - & - & - \\
\hline & Kunming & $36.50(28.90-44.51)$ & 26 \\
\hline & Dalian & $28.94(23.58-37.33)$ & 17 \\
\hline & Guiyang & 31.05 (24.03-39.59) & 16 \\
\hline \multirow[t]{7}{*}{$\mathrm{O}_{3}$} & Wuhan & $79.06(51.67-110.33)$ & 181 \\
\hline & Shanghai & 77.55 (58.89-96.12) & 165 \\
\hline & Ji'nan & $72.48(40.46-102.40)$ & 160 \\
\hline & - & - & - \\
\hline & Zunyi & $64.79(57.48-73.13)$ & 31 \\
\hline & Hefei & $55.23(38.77-67.33)$ & 29 \\
\hline & Fuzhou & $49.42(39.63-62.93)$ & 27 \\
\hline \multirow[t]{7}{*}{$\mathrm{PM}_{10}$} & Xingtai & $251.43(172.92-359.36)$ & 308 \\
\hline & Ji'nan & 166.03 (120.06-237.78) & 215 \\
\hline & Xi'an & 143.05 (98.79-218.76) & 173 \\
\hline & - & - & - \\
\hline & Shenzhen & $59.83(38.44-94.45)$ & 19 \\
\hline & Kunming & 72.19 (46.77-99.89) & 15 \\
\hline & Fuzhou & $62.29(45.56-87.95)$ & 14 \\
\hline \multirow[t]{7}{*}{$\mathrm{PM}_{2.5}$} & Xingtai & 119.29 (78.09-196.94) & 258 \\
\hline & Ji'nan & $84.93(59.76-129.42)$ & 192 \\
\hline & Tianjin & $80.58(54.03-113.46)$ & 178 \\
\hline & - & - & - \\
\hline & Shenzhen & $36.92(21.18-58.11)$ & 27 \\
\hline & Fuzhou & $31.65(20.53-49.52)$ & 12 \\
\hline & Kunming & $37.88(24.00-53.04)$ & 9 \\
\hline \multirow[t]{7}{*}{$\mathrm{SO}_{2}$} & Xingtai & $84.58(51.71-137.72)$ & 291 \\
\hline & Ji'nan & $61.47(40.98-104.46)$ & 256 \\
\hline & Shenyang & $40.98(24.26-98.12)$ & 169 \\
\hline & - & - & - \\
\hline & Wenzhou & $20.14(13.46-29.00)$ & 13 \\
\hline & Guangzhou & $20.19(15.07-26.22)$ & 6 \\
\hline & Shenzhen & $9.83(7.43-14.57)$ & 1 \\
\hline
\end{tabular}

* The days of a specific city that the pollutant concentration exceeds the "extreme value"

air pollution [18]. But there was no consistent view about the effect of different pollutants on DED. There was a study [19] about the relationship between outdoor air 


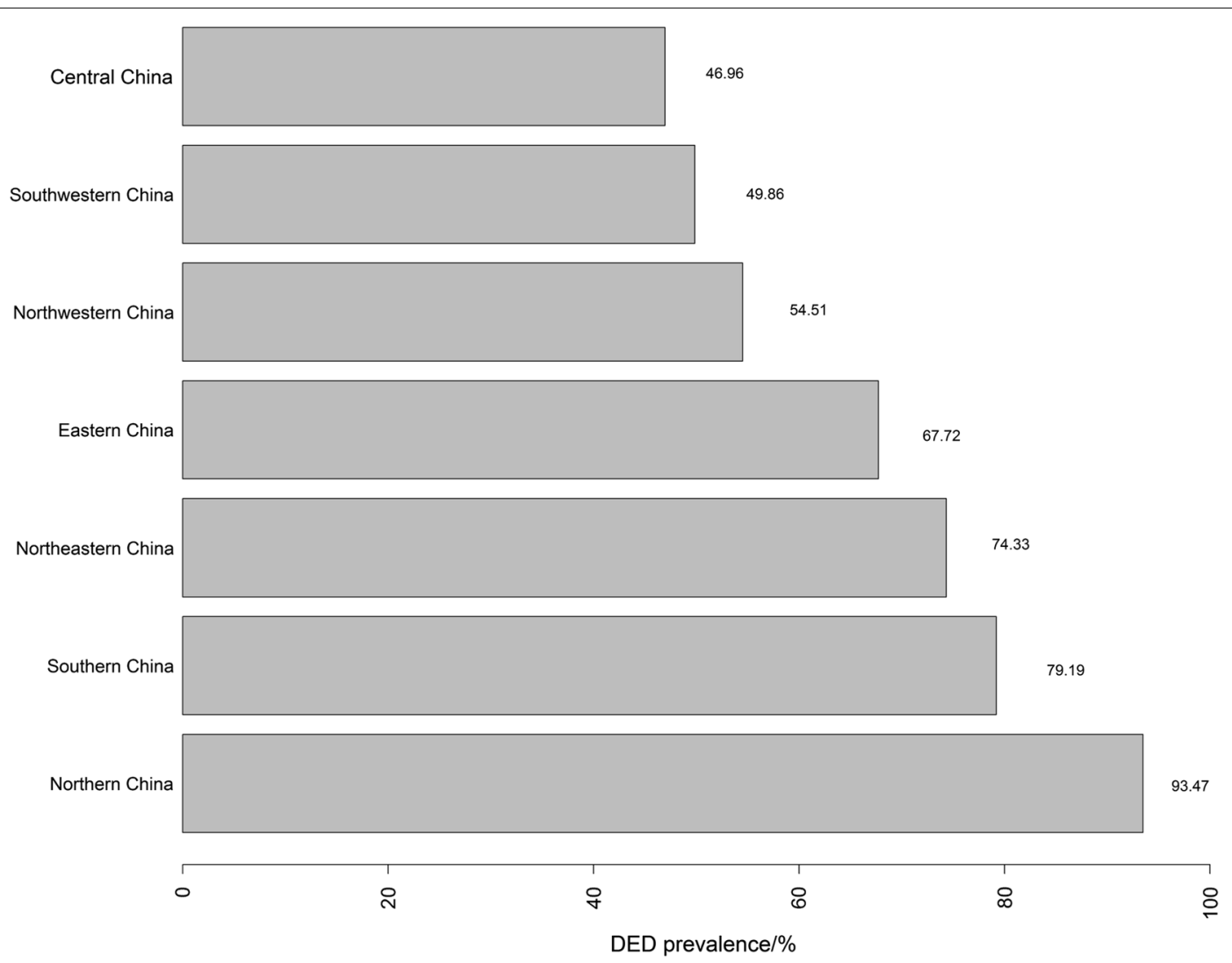

Fig. 1 The prevalence of DED in different areas

pollution and DED: higher $\mathrm{O}_{3}$ levels and lower humidity levels were associated with higher DED prevalence in the Korean population, while PM10 level was not associated with DED. However, in the same country, another study [20] showed a different conclusion: lower humidity and longer sunshine duration were significantly associated with higher DED prevalence and among air pollutants, $\mathrm{SO}_{2}$ was associated with DED, while $\mathrm{NO}_{2}, \mathrm{O}_{3}, \mathrm{CO}$, and $\mathrm{PM}_{10}$ were not. The phosphorylation and interaction of FAK/paxillin, RhoA activity as well as actin reorganization were suppressed by $\mathrm{PM}_{2.5}$ exposure. Moreover, formation of ROS might play a role in the action of $\mathrm{PM}_{2.5}$ [21]. $\mathrm{PM}_{2.5}$ induced apoptosis. Corneal epithelial cells were damaged and $\mathrm{PM}_{2.5}$ exposure could result in delay of corneal epithelium wound healing by inhibiting cell migration [22, 23]. It may be one of the pathogenic factors of DED caused by $\mathrm{PM}_{2.5}$. DED is associated with the inflammatory cascade of Mitogen-Activated Protein (MAP) kinase and Nuclear Factor $\kappa B(N F-k B)$ signaling pathway. Meanwhile, various proinflammatory cytokines (e.g. IL-1 $\alpha$, IL-1 $\beta$, TNF- $\alpha$ ) and Matrix metalloproteinase (e.g. MMP-1, MMP-3, MMP-9, MMP-13) were included in [24-27]. The $\mathrm{O}_{3}$-induced expression of proinflammatory cytokines requires the activation of the epidermal growth factor receptor/MEK/ERK and MKK4/p38 mitogen-activated signaling pathways and NF- $\kappa B$ signaling pathways $[28,29]$. That is probably the pathogeny for DED through $\mathrm{O}_{3}$. In this study, air pollutants including $\mathrm{O}_{3}, \mathrm{PM}_{2.5}$ and $\mathrm{SO}_{2}$ were the potential risk factors for DED and PM10 and $\mathrm{NO}_{2}$ were not associated with DED. However, CO may be the potential protective factor for DED. A study in America showed that increased ambient $\mathrm{NO}_{2}$ was consistently associated with increased prevalence of allergic sensitization [30]. But no evidences indicated the relationship between $\mathrm{NO}_{2}$ and DED prevalence. These findings need to be confirmed by large prospective studies and the mechanism remains to be discovered. As a ecological study, some problems still exist. Although some confounding factors were controlled in this study including relative humidity, mean air pressure, and air temperature, more confounding factors cannot be controlled by our study (such as individuals' life styles and gene). It is the defect of our study and other ecological studies.

Many diseases were associated with DED. Our study showed that the history of arthritis diseases was one of the risk factors of DED. Dry eye is common in early Graves' ophthalmopathy even in the absence of apparent 


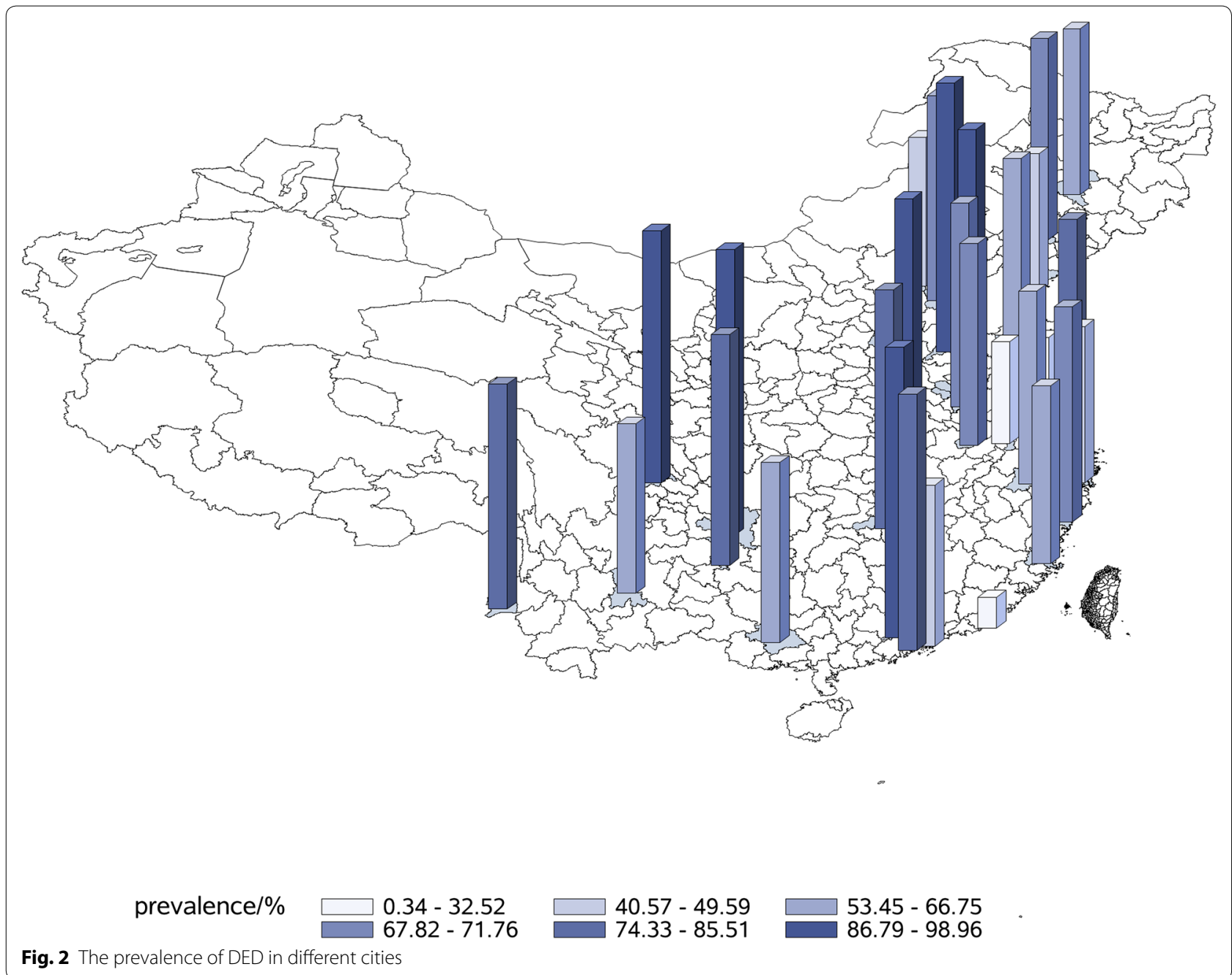

exophthalmos and reduced corneal sensitivity [31]. In thyroid diseases, autoantibodies may bind to lacrimal TSH receptor and, perhaps via aberrant signal transduction, contribute to lacrimal gland impairment and, hence, dry eye syndrome [32]. A study showed that the tear film and cornea were damaged in newly non-exophthalmic Graves' disease subjects [33]. Meanwhile, another survey [34] showed the significantly higher tear film osmolarity in patients with thyroid ophthalmopathy was most likely due to the increased proptosis and lid fissure width. These conditions may lead to injury of the ocular surface. Tear film instability and tear hyperosmolarity played major roles in the vicious circle of DED pathology. Hyperosmolarity directly caused cell damage and nerve stimulation and triggered inflammatory cascades. These cascades then contributed to further cell damage, including loss of mucin-producing goblet cells [35]. This study showed the same result as these previous studies. In the past decades of years, many researches have studied the mechanism of diabetes associated with dry eye in the structure of tear film [36], tear secretion and its disfunction of the autonomic nervous system in diabetic patients [37]. A recent study showed that corneal sensation was reduced in diabetic patients and progresses with the severity of neuropathy, suggesting that corneal nerve fibre damaged accompanying somatic nerve fibre damage [38]. These findings were consistent with a meta-analysis in mainland China: diabetes is a potential risk factor for DED [39]. However, data in this research indicated that diabetes was not significantly associated with DED. One explanation is that some of these outpatients have had DED before they were diagnosed with diabetes. This is one of the limitations of cross-sectional study. One study [40] revealed that meibomian gland function is influenced after ocular surgery accompanying structural changes and these were correlated with increased ocular symptom scores. Therefore, it could elucidate the development of dry eye related to ocular surgery. Our study also demonstrated an association between corneal refractive surgery and DED, which is consistent with the findings of previous studies. 
Table 3 Multivariate logistic regression analysis of risk factors for DED

\begin{tabular}{|c|c|c|c|c|c|}
\hline Characteristics & $\beta$ & OR & $95 \% \mathrm{Cl}$ & Wald $x^{2}$ & $P$ value \\
\hline \multicolumn{6}{|l|}{ Gender } \\
\hline Male & Ref & Ref & - & - & - \\
\hline Female & 0.4079 & 1.504 & $(1.421,1.592)$ & 197.6858 & $<0.0001$ \\
\hline \multicolumn{6}{|l|}{ Age (years old) } \\
\hline$<25$ & Ref & Ref & - & - & - \\
\hline $25-45$ & 0.4540 & 1.575 & $(1.462,1.696)$ & 143.6879 & $<0.0001$ \\
\hline$>45$ & 0.9010 & 2.462 & $(2.267,2.675)$ & 453.8747 & $<0.0001$ \\
\hline \multicolumn{6}{|c|}{ Keratorefractive surgery } \\
\hline No & Ref & Ref & - & - & - \\
\hline Yes & 0.5449 & 1.724 & $(1.588,1.874)$ & 166.8826 & $<0.0001$ \\
\hline \multicolumn{6}{|l|}{ Arthritis } \\
\hline No & Ref & Ref & - & - & - \\
\hline Yes & 0.5060 & 1.659 & $(1.483,1.857)$ & 77.8043 & $<0.0001$ \\
\hline \multicolumn{6}{|l|}{ Thyroid diseases } \\
\hline No & Ref & Ref & - & - & - \\
\hline Yes & 0.2502 & 1.284 & $(1.139,1.449)$ & 16.6104 & $<0.0001$ \\
\hline \multicolumn{6}{|l|}{ Antihistamine } \\
\hline No & Ref & Ref & - & - & - \\
\hline Yes & 0.4004 & 1.492 & $(1.321,1.689)$ & 40.9029 & $<0.0001$ \\
\hline \multicolumn{6}{|l|}{ OC } \\
\hline No & Ref & Ref & - & - & - \\
\hline Yes & -0.3023 & 0.739 & $(0.632,0.865)$ & 14.3181 & 0.0002 \\
\hline \multicolumn{6}{|l|}{ Diuretics } \\
\hline No & Ref & Ref & - & - & - \\
\hline Yes & 0.2087 & 1.232 & $(1.061,1.433)$ & 7.4087 & 0.0065 \\
\hline \multicolumn{6}{|l|}{ DU drugs } \\
\hline No & Ref & Ref & - & - & - \\
\hline Yes & 0.5263 & 1.693 & $(1.372,2.101)$ & 23.4873 & $<0.0001$ \\
\hline \multicolumn{6}{|l|}{ Diazepam } \\
\hline No & Ref & Ref & - & - & - \\
\hline Yes & 0.4334 & 1.542 & $(1.289,1.855)$ & 21.7865 & $<0.0001$ \\
\hline \multicolumn{6}{|l|}{$\mathrm{CO}($ days)* } \\
\hline$<124$ & Ref & Ref & - & - & - \\
\hline$\geq 124$ & -0.7163 & 0.489 & $(0.424,0.563)$ & 97.1635 & $<0.0001$ \\
\hline \multicolumn{6}{|l|}{$\mathrm{NO}_{2}$ (days) $)^{*}$} \\
\hline$<150$ & Ref & Ref & - & - & - \\
\hline$\geq 150$ & -0.1010 & 0904 & $(0.834,0.980)$ & 5.9988 & 0.0143 \\
\hline \multicolumn{6}{|l|}{$\mathrm{O}_{3}$ (days)* } \\
\hline$<125$ & Ref & Ref & - & - & - \\
\hline$\geq 125$ & 1.3777 & 3.966 & $(3.666,4.293)$ & 1171.6734 & $<0.0001$ \\
\hline \multicolumn{6}{|l|}{$\mathrm{PM}_{2.5}$ (days) $^{*}$} \\
\hline$<143$ & Ref & Ref & - & - & - \\
\hline$\geq 143$ & 0.6971 & 2.008 & $(1.789,2.255)$ & 139.8619 & $<0.0001$ \\
\hline \multicolumn{6}{|l|}{$\mathrm{SO}_{2}$ (days)* } \\
\hline$<101$ & Ref & Ref & - & - & - \\
\hline$\geq 101$ & 0.4941 & 1.639 & $(1.503,1.788)$ & 123.9515 & $<0.0001$ \\
\hline
\end{tabular}

Factors controlled: relative humidity, mean air pressure, and air temperature * The number of days in which the pollutant concentration exceeds "extreme value"
Many different drugs will influence on DED. The effect of antihistamines on dry eye has been unanimously recognized by scholars all over the world and this study got the same conclusion. The finding in Wisconsin [41] showed that dry eye could be related to the use of antihistamines that have anticholinergic properties owing to high muscarinic receptor binding. Systemic antihistamines, including old and newer generations, have been shown to potentially cause clinically meaningful damage to the ocular surface as a result of anti-muscarinic activity on the M3 receptors that results in a decrease in both aqueous and mucin tear [42]. There is no consensus of opinion about the effect of estrogen on DED. A previous study [43] showed phytoestrogen supplementation can significantly improve the signs and symptoms of dry eye syndrome in postmenopausal women. But latest survey showed another opinion: Serum hormone levels did not contribute significantly to dry eye symptoms. In our study, OC, a kind of estrogen, showed significant protective effect on DED. Whether estrogen can affect DED and what's the potential mechanism needs further studies. As for diuretics, this study showed that diuretics was a risk factor for DED. However, there was no relevant research supporting this finding and a hypothesis is that it might be related to the function of diuretics that can reduce systemic circulation volume. But this assumption needs to be verified by experiment in future. Previous study indicated that medications prescribed for psychiatric conditions may precipitate DED [44]. It may be the reason that diazepam is a risk factor of DED. Meanwhile, the results of several previous researches suggested a reciprocal relationship between DED and sleep disorders, particularly in elderly patients $[45,46]$. Diazepam is generally used by patients with sleep disorders. The relationship between diazepam and DED discovered in this study may be caused by sleep disorders instead of the effect of diazepam, and this remains further exploration.

This cross-sectional study revealed the prevalence and risk factors for DED among ophthalmic outpatients in China. However, exposure to sunlight was not considerated and factors affecting the severity of DED were not clear. Consequently, a further study about the potential influence factors for sunlight and the severity of DED was expected in future. Meanwhile, Besides, the findings of this research should be generalized to a population derived from communities rather than ophthalmic clinics. Thirdly, a prospective cohort study was expected to demonstrate the risk factors of DED. Last but not least, studies in other countries, regions, or ethnic groups were needed with equal importance. 


\section{Conclusion}

This present study suggested that the prevalence of DED among ophthalmic outpatients in China was considerably high. The significant associated factors for DED included age, gender, history of keratorefractive surgery, diseases (arthritis, thyroid diseases), medication history (using antihistamine, diuretic, duodenal ulcer drugs, diazepam, oral contraceptive), and air pollutants $\left(\mathrm{O}_{3}, \mathrm{PM}_{2.5}, \mathrm{SO}_{2}\right.$, $\mathrm{CO}, \mathrm{NO}_{2}$ ).

\section{Abbreviations}

DED: dry eye disease; OR: odds ratios; $\mathrm{Cl}$ : confidence intervals; $\mathrm{P}$ : $\mathrm{P}$ value; $\mathrm{O}_{3}$ : ozone; $\mathrm{NO}_{2}$ : nitrogen dioxide; $\mathrm{PM}_{25}$ : particulate matter $2.5 ; \mathrm{PM}_{10}$ : particulate matter $10 ; \mathrm{SO}_{2}$ : sulfur dioxide; OC: oral contraceptive.

\begin{abstract}
Authors' contributions
Jing $Y$ and Jinm $Y$ conceived the idea for the study and managed the project. JinmY and JW designed the study. DY, QD, JW, RY, JinmY, and Jing Y conducted the survey across China and collected the DED data. QD performed the statistical analyses and wrote the statistical analysis plan. XC and SW provided the ambient air pollutant data. DY wrote the manuscript and prepared the figures and tables. DY, QD, JW, JinmY, and JingY revised the manuscript. All authors interpreted the data and contributed to preparation of the manuscript. No conflicting relationship exists for any author. Prof. J Yu and Prof. JM Yu are both corresponding authors of this paper. All authors read and approved the final manuscript.
\end{abstract}

\section{Author details}

${ }^{1}$ Department of Ophthalmology, Shanghai Tenth People's Hospital, School of Medicine, Tongji University, No. 301, Yanchang Road, Shanghai, China. ${ }^{2}$ School of Medicine, Tongji University, No. 1239, Siping Road, Shanghai, China. ${ }^{3}$ Institute of Clinical Epidemiology, School of Public Health and Key Laboratory of Public Health Safety, Ministry of Education, Fudan University, No. 138, Yixueyuan Road, Shanghai, China. ${ }^{4}$ School of Environment, Tsinghua University, No. 1, Tsinghua Yuan, Haidian District, Beijing, China.

\section{Acknowledgements}

We are grateful to the help of these hospital: Beijing (The second hospital of Chaoyang District, Aerospace Center Hospital, Peking University People's Hospital, Peking Union Medical College Hospital, Beijing Ditan Hospital, Beijing Tongren Hospital (West), Peking University First Hospital, Beijing Pinggu Hospital, Air force organ Hospital of Beijing Military Area Command, Peking University Third Hospital, and Beijing Tongren Hospital), Changchun (The Second Hospital of Jilin University), Changsha (Xiangya Hospital Central South University and Hunan Children's Hospital), Chengdu (Aier Eye Hospital and West China Hospital and Sichuan University), Chengde (Affiliated Hospital of Chengde Medical University), Dalian (The Third People's Hospital of Dalian and The Second Hospital of Dalian Medical University), Foshan (The Second People's Hospital of Foshan), Fuzhou (Fuzhou South East Eye Hospital), Guangzhou (Zhongshan Ophthalmic Center, Sun Yat-Sen University, Second Affiliated Hospital of Sun Yat-Sen University, Guangdong General Hospital, and Guangzhou Women and Children's Medical Center), Guiyang (Chinese People's Liberation Army No. 44 Hospital), Hangzhou (Hangzhou Third Hospital, The First People's Hospital of Chunan County, Zhejiang Provincial People's Hospital, Hangzhou Second Hospital, Zhejinag Hospital, The First Affiliated Hospital of Zhejiang University, and Tongde Hospital of Zhejiang Province), Hefei (The First Affiliated Hospital of Anhui Medical University and Anhui Provincial Hospital), Jinan (Jinan Mingshui Eye Hospital and Qilu Hospital of Shandong University), Kunming (The First People's Hospital of Yunnan Province), Nanjing (The Second Affiliated Hospital of Nanjing Medical University and Nanjing General Hospital), Nanning (The People's Hospital of Guangxi Zhuang Autonomous Region and The First Affiliated Hospital of Guangxi Medical University), Ningbo (The Second People's Hospital of Cixi, Zongrui Hospital, Guangming Eye Hospital, and The First People's Hospital of Ninghai County), Qingdao (Qingdao Eye Hospital), Shantou (Shantou Central Hospital), Shanghai (Shanghai Tenth People's Hospital, Shanghai Heping Eye Hospital, Shanghai Sixth
People's Hospital, Huashan Hospital Affiliated to Fudan University, Shuguang Hospital and Eye \& Ent Hospital of Fudan University), Shenzhen (Peking University Shenzhen Hospital, Shenzhen Second People's Hospital, and Shenzhen People's Hospital), Shenyang (The 4th People's Hospital of Shenyang and Chinese People's Liberation Army No. 463 Hospital), Suzhou (The First People's Hospital of Wujiang District), Tianjin (Tianjin Medical UNiversity Eye Hospital and Tianjin Children's Hospital), Wenzhou (Leqing People's Hospital, The Eye Hospital of WMU (Hangzhou), and The Eye Hospital of WMU), Wuxi (Wuxi Third People's Hospital), Wuhan (Wuhan Union Hospital, Wuhan General Hospital, Wuhan Aier Eye Hospital and The Central Hospital of Wuhan), Xi'an (Xi'an No.4 Hospital and The First Affiliated Hospital of Xi'an Jiaotong University), Xingtai (Hebei Eye Hospital), Xuzhou (Xuzhou Central Hospital and The First People's Hospital of Xuzhou), and Zhongshan (Zhongshan People's Hospital), Zunyi (Affiliated Hospital of Zunyi Medical College).

\section{Competing interests}

The authors declare that they have no competing interests.

\section{Availability of data and materials}

All data generated or analyzed during this study are included in this published article and its additional file.

\section{Consent for publication}

Each person provided signed informed consent for publication of the results of the study.

\section{Ethics approval and consent to participate}

This survey was approved by Medical Research Ethics Committee of School of Public Health, Fudan University. Details and procedures of this study were indicated to all the patients by practitioners before the survey and clinical tests. Informed consent was obtained from all the subjects. Participants who disagreed with this survey would be excluded, thus, in this way we documented and insured all patient consents.

\section{Funding}

There is no fund for this research.

\section{Publisher's Note}

Springer Nature remains neutral with regard to jurisdictional claims in published maps and institutional affiliations.

Received: 28 November 2018 Accepted: 5 February 2019

Published online: 15 February 2019

\section{References}

1. Schirmer O. Studien zur Physiologie und Pathologie der Tränenabsonderung und Tränenabfuhr. Albrecht von Graefes Archiv für Ophthalmologie. 1903:56:197-291.

2. Lemp MA. Report of the National Eye Institute/Industry workshop on Clinical Trials in Dry Eyes. Clao J. 1995;21:221.

3. Smith JA, Albeitz J, Begley C, Caffery B, Nichols K, Schaumberg D, Schein O. The epidemiology of dry eye disease: report of the epidemiology subcommittee of the international dry eye workshop. Ocul Surf. 2007;2007:93-107.

4. Tsubota K, Yokoi N, Shimazaki J, Watanabe H, Dogru M, Yamada M, Kinoshita S, Kim H-M, Tchah H-W, Hyon JY, et al. New perspectives on dry eye definition and diagnosis: a consensus report by the Asia Dry Eye Society. Ocul Surf. 2017;15:65-76.

5. Schaumberg DA, Sullivan DA, Buring JE, Dana MR. Prevalence of dry eye syndrome among US women. Am J Ophthalmol. 2003;136:318-26.

6. Uchino M, Nishiwaki Y, Michikawa T, Shirakawa K, Kuwahara E, Yamada M, Dogru M, Schaumberg DA, Kawakita T, Takebayashi T, Tsubota K. Prevalence and risk factors of dry eye disease in Japan: Koumi Study. Ophthalmology. 2011;118:2361-7.

7. Onwubiko SN, Eze BI, Udeh NN, Arinze OC, Onwasigwe EN, Umeh RE. Dry eye disease: prevalence, distribution and determinants in a hospitalbased population. Cont Lens Anterior Eye. 2014;37:157-61. 
8. Schein OD, Munoz B, Tielsch JM, Bandeen-Roche K, West S. Prevalence of dry eye among the elderly. Am J Ophthalmol. 1997;124:723-8.

9. Moss SE, Klein R, Klein BE. Prevalence of and risk factors for dry eye syndrome. Arch Ophthalmol. 2000;1 18:1264-8.

10. Jo EJ, Lee WS, Jo HY, Kim CH, Eom JS, Mok JH, Kim MH, Lee K, Kim KU, Lee MK, Park HK. Effects of particulate matter on respiratory disease and the impact of meteorological factors in Busan, Korea. Respir Med. 2017;124:79-87.

11. Fukuda T, Ohashi N, Doi K, Matsubara T, Kitsuta Y, Kitsuta Y, Nakajima S, Yahagi N. Impact of seasonal temperature environment on the neurologic prognosis of out-of-hospital cardiac arrest: a nationwide, population-based cohort study. J Crit Care. 2014;29:840-7.

12. Raaschou-Nielsen $O$, Pedersen M, Stafoggia M, Weinmayr G, Andersen ZJ, Galassi C, Sommar J, Forsberg B, Olsson D, Oftedal B, et al. Outdoor air pollution and risk for kidney parenchyma cancer in 14 European cohorts. Int J Cancer. 2017;140:1528-37.

13. Janitz AE, Campbell JE, Magzamen S, Pate A, Stoner JA, Peck JD. Trafficrelated air pollution and childhood acute leukemia in Oklahoma. Environ Res. 2016;148:102-11.

14. Teson M, Lopez-Miguel A, Neves H, Calonge M, Gonzalez-Garcia MJ, Gonzalez-Meijome JM. Influence of climate on clinical diagnostic Dry Eye Tests: pilot Study. Optom Vis Sci. 2015;92:e284-9.

15. Mcmonnies CW, Ho A. Patient history in screening for dry eye conditions. J Am Optom Assoc. 1987;58:296-301.

16. Chinese Medical Association OB. The keratonosus group: expert consensus on clinical diagnosis and treatment of dry eye. Chin J Ophthalmol. 2013:49:73-5.

17. Alves M, Novaes P, Morraye MA, Reinach PS, Rocha EM. Is dry eye an environmental disease? Arquivos Brasileiros De Oftalmologia. 2014;77:193-200.

18. Galor A, Kumar N, Feuer W, Lee DJ. Environmental factors affect the risk of dry eye syndrome in a United States veteran population. Ophthalmology. 2014;121:972

19. Hwang SH, Choi YH, Paik HJ, Wee WR, Kim MK, Kim DH. Potential importance of ozone in the association between outdoor air pollution and dry eye disease in South Korea. JAMA Ophthalmol. 2016;134(5):503-10.

20. Um SB, Na HK, Lee HK, Song JS, Kim HC. Spatial epidemiology of dry eye disease: findings from South Korea. Int J Health Geogr. 2014;13:31.

21. Cui YH, Hu ZX, Gao ZX, Song XL, Feng QY, Yang G, Li ZJ, Pan HW. Airborne particulate matter impairs corneal epithelial cells migration via disturbing FAK/RhoA signaling pathway and cytoskeleton organization. Nanotoxicology. 2018;12:1-13.

22. Fu Q, Lyu D, Zhang L, Qin Z, Tang Q, Yin H, Lou X, Chen Z, Yao K. Airborne particulate matter (PM25) triggers autophagy in human corneal epithelial cell line. Environ Poll. 2017;227:314.

23. Gao ZX, Song XL, Li SS, Lai XR, Yang YL, Yang G, Li ZJ, Cui YH, Pan HW. Assessment of DNA damage and cell senescence in corneal epithelial cells exposed to airborne particulate matter (PM25) collected in Guangzhou, China. Invest Ophthalmol Vis Sci. 2016;57:3093.

24. De-Quan L, Zhuo C, Jun SX, Lihui L, Pflugfelder SC. Stimulation of matrix metalloproteinases by hyperosmolarity via a JNK pathway in human corneal epithelial cells. Invest Ophthalmol Vis Sci. 2013;45:4302.

25. Lihui L, De-Quan L, Corrales RM, Pflugfelder SC. Hyperosmolar saline is a proinflammatory stress on the mouse ocular surface. Eye Contact Lens. 2005;31:186-93.

26. Paiva CSD, Corrales RM, Villarreal AL, Farley WJ, Li DQ, Stern ME, Pflugfelder SC. Corticosteroid and doxycycline suppress MMP-9 and inflammatory cytokine expression, MAPK activation in the corneal epithelium in experimental dry eye. Exp Eye Res. 2006;83:526-35.

27. Guzmán M, Keitelman I, Sabbione F, Trevani AS, Giordano MN, Galletti JG. Desiccating-stress-induced disruption of ocular surface immune tolerance drives dry eye disease. Clin Exp Immunol. 2016;184:248-56.

28. Mccullough SD, Duncan KE, Swanton SM, Dailey LA, David DS, Devlin RB. Ozone induces a proinflammatory response in primary human bronchial epithelial cells through mitogen-activated protein kinase activation without nuclear factor-kB activation. Am J Respir Cell Mol Biol. 2014;51:426-35.

29. Weidong W, Vinod D, David DS, Samet JM, Matt K, Lisa D, Wenli Z, Ilona J, Peden DB. GSTM1 modulation of IL-8 expression in human bronchial epithelial cells exposed to ozone. Free Radical Biol Med. 2011;51:522-9.
30. Weir CH, Yeatts KB, Sarnat JA, Vizuete W, Salo PM, Jaramillo R, Cohn RD, Chu H, Zeldin DC, London SJ. Nitrogen dioxide and allergic sensitization in the 2005-2006 National Health and Nutrition Examination Survey. Respir Med. 2013;107:1763.

31. Achtsidis V, Tentolouris N, Theodoropoulou S, Panagiotidis D, Vaikoussis E, Saldana M, Gouws P, Theodossiadis PG. Dry eye in Graves ophthalmopathy: correlation with corneal hypoesthesia. Eur J Ophthalmol. 2013;23:473-9.

32. Eckstein AK, Finkenrath A, Heiligenhaus A, Renzing-Kohler K, Esser J, Kruger C, Quadbeck B, Steuhl KP, Gieseler RK. Dry eye syndrome in thyroid-associated ophthalmopathy: lacrimal expression of TSH receptor suggests involvement of TSHR-specific autoantibodies. Acta Ophthalmol Scand. 2004:82:291-7.

33. Bruscolini A, Abbouda A, Locuratolo N, Restivo L, Trimboli P, Romanelli F. Dry eye syndrome in non-exophthalmic Graves' disease. Semin Ophthalmol. 2015;30:372-6.

34. Iskeleli $\mathrm{G}$, Karakoc Y, Abdula A. Tear film osmolarity in patients with thyroid ophthalmopathy. Jpn J Ophthalmol. 2008;52:323-6.

35. Baudouin C, Aragona P, Messmer EM, Tomlinson A, Calonge M, Boboridis KG, Akova YA, Geerling G, Labetoulle M, Rolando M. Role of hyperosmolarity in the pathogenesis and management of dry eye disease: proceedings of the OCEAN group meeting. Ocul Surf. 2013;11:246-58.

36. Zhang $X$, Zhao L, Deng $S$, Sun $X$, Wang N: Dry Eye Syndrome in Patients with Diabetes Mellitus: Prevalence, Etiology, and Clinical Characteristics. J Ophthalmol 2016, 2016

37. Ramos-Remus C, Suarez-Almazor M, Russell AS. Low tear production in patients with diabetes mellitus is not due to Sjogren's syndrome. Clin Exp Rheumatol. 1994;12:375-80

38. Tavakoli M, Kallinikos PA, Efron N, Boulton AJ, Malik RA. Corneal sensitivity is reduced and relates to the severity of neuropathy in patients with diabetes. Diabetes Care. 2007;30:1895-7.

39. Liu NN, Liu L, Li J, Sun YZ. Prevalence of and risk factors for dry eye symptom in mainland china: a systematic review and meta-analysis. J Ophthalmol. 2014;2014:748654.

40. Park Y, Hwang HB, Kim HS. Observation of Influence of Cataract Surgery on the Ocular Surface. PLoS ONE. 2016;11:e0152460.

41. Bielory L. Role of antihistamines in ocular allergy. Am J Med. 2002;113:34-7.

42. Lekhanont K, Park CY, Combs JC, Suwan-Apichon O, Rangsin R, Chuck RS. Effect of topical olopatadine and epinastine in the botulinum toxin B-induced mouse model of dry eye. J Ocul Pharmacol Ther. 2007;23:83-8.

43. Scuderi G, Contestabile MT, Gagliano C, lacovello D, Scuderi L, Avitabile T. Effects of phytoestrogen supplementation in postmenopausal women with dry eye syndrome: a randomized clinical trial. Can J Ophthalmol. 2012;47:489-92.

44. Galor A, Feuer W, Lee DJ, Florez H, Carter D, Pouyeh B, Prunty WJ, Perez VL. Prevalence and risk factors of dry eye syndrome in a United States veterans affairs population. Am J Ophthalmol. 2011;152(377-384):e372.

45. Galor A, Seiden BE, Park JJ, Feuer WJ, McClellan AL, Felix ER, Levitt RC, Sarantopoulos CD, Wallace DM. The association of dry eye symptom severity and comorbid insomnia in US veterans. Eye Contact Lens. 2017;44:S118-24.

46. Lee W, Lim SS, Won JU, Roh J, Lee JH, Seok H, Yoon JH. The association between sleep duration and dry eye syndrome among Korean adults. Sleep Med. 2015;16:1327-31.

Ready to submit your research? Choose BMC and benefit from:

- fast, convenient online submission

- thorough peer review by experienced researchers in your field

- rapid publication on acceptance

- support for research data, including large and complex data types

- gold Open Access which fosters wider collaboration and increased citations

- maximum visibility for your research: over $100 \mathrm{M}$ website views per year

At BMC, research is always in progress.

Learn more biomedcentral.com/submissions 